\title{
Comparing burnout in emergency nurses and medical
}

\section{nurses}

\author{
Maureen Harkin ${ }^{1}$, Vidar Melby² \\ 1. Emergency Department, Letterkenny General Hospital, Letterkenny, Republic of Ireland. 2. School of Nursing, \\ University of Ulster, Derry, United Kingdom.
}

Correspondence: Maureen Harkin. Address: Craigdoo, Convoy, Co. Donegal, Ireland. Email: harkin-m@hotmail.com

Received: December 19, 2013

Accepted: J une 22, 2014

Online Published: June 29, 2014

DOI : $10.5430 /$ cns.v2n3p152

URL: http://dx.doi.org/10.5430/cns.v2n3p152

\section{Abstract}

Aims: This paper reports the findings of a study that aimed to determine and compare the prevalence of burnout between emergency nurses and medical nurses, and to examine how burnout was influenced by a range of job-related and personal factors.

Methods: The study incorporated a descriptive quantitative design, and based in a Regional General Hospital in the Republic of Ireland, a total population sample of 61 emergency nurses and medical nurses working on one acute medical unit were asked to participate. A validated tool was used to measure burnout levels, and an instrument was designed to capture job-related and personal data that were deemed to be potentially important on the basis of existing evidence.

Results: A response rate of $78.6 \%(n=48)$ was obtained. Although the results need to be interpreted with caution, analysis revealed no significant difference in Emotional Exhaustion, Depersonalisation or Personal Accomplishment levels between medical nurses and emergency nurses. The job-related and personal factors of gender, age, marital status and the number of hours worked per week were significantly $(p<.05)$ associated with burnout.

Conclusion: The findings of this study consolidate existing knowledge on burnout in nurses and confirm that burnout is prevalent in emergency and medical nurses. The findings have also identified nursing groups that have higher levels of burnout so that burnout reduction measures can be targeted at them.

\section{Key words}

Burnout, Medical nurses, Emergency nurses

\section{Introduction}

Burnout has been widely studied in the health service professions and nursing is recognised as one of the occupations with the highest burnout prevalence rates ${ }^{[1]}$ and has a negative impact for the organisation, the individual nurse and the patient. According to Scott ${ }^{[2]}$ outcomes of workplace burnout are linked to costly increases in staff turnover, absenteeism, and reduced productivity for the individual and the organisation. Irish nurses face immense challenges in the light of recent developments in the health service that include a recruitment moratorium ${ }^{[3]}$ and a reform of public sector pay ${ }^{[4]}$. Kilcoyne and Dowling ${ }^{[5]}$ reported that Irish nurses felt frustrated, angry and stressed working in an unhealthy environment which they felt had become the accepted norm. 


\section{Background}

The term burnout was first introduced by Herbert Freudenberger, a German-born American psychologist, who explored the phenomenon of burnout as a result of his work with substance abusers and his personal experience of feelings of burnout ${ }^{[6]}$. The concept was further developed by the American social psychologist Christina Maslach, who defined burnout as a psychological response to chronic emotional and interpersonal stressors in one's job ${ }^{[7]}$. This definition is based on the three dimensions that are viewed as forming the burnout construct, namely; Emotional Exhaustion, Depersonalisation and Reduced Personal Accomplishment. Emotional Exhaustion is viewed as the effort to distance oneself emotionally and cognitively from one's work and is considered the central element of burnout and the most obvious manifestation of the syndrome ${ }^{[8]}$. Depersonalisation refers to the negative and cynical confrontation of service users ${ }^{[9]}$, and reduced Personal Accomplishment refers to a decline in one's feelings of competence and successful achievement in one's work with people ${ }^{[10]}$. Burnout has been linked to compassion fatigue ${ }^{[11,12]}$, a term that describes the weariness and stress felt by some nurses as they struggle to sustain the ability to witness and respond to profound suffering in their patients ${ }^{[13]}$. Although burnout and compassion fatigue are closely related it is generally accepted that compassion fatigue results primarily from relational connections that nurses have formed ${ }^{[14,15]}$. According to Figley ${ }^{[16]}$ the presence of burnout could increase the likelihood of developing compassion fatigue. Maslach and Leiter ${ }^{[17]}$ formulated a model of burnout that suggests that burnout occurs when there is a mismatch between the person and any of the six domains of his or her job environment, namely: workload, control, reward community, fairness and values. The greater the degree of mismatch between the person and any of these areas the greater the likelihood of burnout occurring.

The existence of burnout in nurses is acknowledged universally. The World Health Organisation ${ }^{[18]}$ has recognised burnout in its International Statistical Classification of Diseases and Related Health Problems (ICD-10). Burnout is well recognised in the health services sector and nurses are cited as some of the professionals most susceptible to burnout ${ }^{[19]}$. According to Lei, Hee \& Dong ${ }^{[20]}$ burnout in nurses has become increasingly more commonplace in developed countries and suggested this poses a threat to healthcare systems. Lack of time to plan and prepare work, frequent interruptions, and responsibility in the absence of decision-making power, are serious stressors for nurses ${ }^{[1]}$.

Burnout has implications for the individual nurse and the patient. The individual experiencing burnout may have non-specific symptoms that can include tiredness, insomnia, headaches, eating problems, irritability, emotional instability and rigidity in relationships ${ }^{[21]}$. Burnout can have a negative effect on patient satisfaction ${ }^{[22]}$ with patients being less satisfied on units were nurses feel more exhausted ${ }^{[23]}$.

Burnout can have serious consequences for the retention of nurses within an organisation. In a study of 10,184 staff nurses in Pennsylvania, Aiken, Clarke, Sloane, Sochalski \& Silber ${ }^{[24]}$ found that $43 \%$ of nurses who reported high levels of burnout and dissatisfaction with their job intended to leave their current job within 12 months. Poncet et al ${ }^{[21]}$, in a study of 2,497 intensive care nurses, found that $60 \%$ of respondents with severe levels of burnout reported thinking about changing to another profession. Increased workload has been shown to have a negative impact on job satisfaction and burnout. Aiken et al ${ }^{[24]}$ in a study of US hospital nurses found that an increase of one patient per nurse to a hospital's staffing level increased burnout and job dissatisfaction by $23 \%$ and $15 \%$ respectively.

The relationship between job-related and personal factors and burnout has been examined in previous research. High levels of burnout are associated with younger nurses ${ }^{[7]}$, and it is suggested that younger nurses experience early burnout due to high expectations and the lack of skills to adapt to the work situation ${ }^{[25]}$. Females are considered to be more prone to stress and this in turn is associated with increased levels of burnout ${ }^{[26]}$. The findings of previous studies on the relationship between marital status and burnout have been mixed. Akgun, Al-Assaf \& Bakan ${ }^{[27]}$ reported that single nurses had higher burnout levels, while Lin, St John \& McVeigh ${ }^{[28]}$ in a study of 249 Chinese nurses found that married nurses had significantly higher levels of burnout. Lin et al ${ }^{[28]}$ pointed out that cultural factors may have influenced the levels of burnout reported by nurses in the study. Such cultural influences are well documented by other researchers ${ }^{[29,30]}$ and include factors such as gender role expectations, religion, role of the family and health care systems. Burnout has been 
linked to increased absenteeism from work ${ }^{[31]}$, and it has been suggested that absenteeism is a form of stress management for the nurse experiencing high levels of chronic stress ${ }^{[32]}$.

While many studies have focused on burnout in intensive care unit nurses ${ }^{[21,33,34]}$, psychiatric nurses ${ }^{[35,36]}$, and oncology

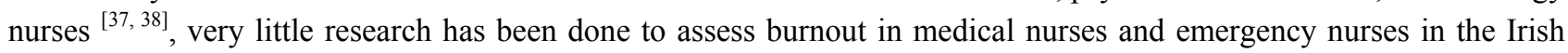
context. Emergency nurses are recognised as being exposed to serious stressors and are considered at risk of burnout ${ }^{[39]}$ and according to Browning, Ryan, Thomas, Greenberg \& Rolniak ${ }^{[40]}$ emergency nurses regularly confront time and other uncontrollable stressors. A study of perceived stress in nurses working in Ireland revealed that perceived stress levels were significantly higher in the Medical ward, Emergency Department, Intensive Care Unit and Paediatric wards than in the Outpatients Department ${ }^{[41]}$. Escriba- Aguir, Martín-Baena \& Pérez-Hoyos ${ }^{[42]}$ in a cross-sectional survey of 945 Spanish emergency doctors and nurses found that high levels of psychological demands, alongside a range of other job-related factors, increased the risk of emotional exhaustion, one of the central domains of burnout. Gillespie and Melby ${ }^{[43]}$ in a triangulated research design of Emergency Department and Acute Medical nurses concluded that stress and burnout have far-reaching effects for nurses in their clinical practice and in life outside the clinical area.

\section{The Study}

\subsection{Research objectives}

The purpose of the study was:

I. to determine the prevalence of burnout in emergency nurses and medical nurses,

II. to determine if there is a difference in burnout between emergency nurses and medical nurses,

III. to examine the relationship between job-related and personal factors and burnout.

\subsection{Design}

This study adopted a descriptive survey design, commonly employed in previous research on this topic ${ }^{[25,38,44,45]}$. Descriptive research is useful in a study that aims to identify individuals' emotional or psychological responses to a set situation ${ }^{[46]}$.

\subsection{Research instrument}

A demographic instrument was developed by the authors to capture personal information on age, gender and marital status. Job-related data were sought in relation to the clinical areas worked in, length of time working in that clinical area, hours worked per week, number of sick days taken in the previous 12 months, and intent to leave the profession.

The Maslach Burnout Inventory - Human Services Survey (MBI) ${ }^{[47]}$ was used to measure levels of burnout in emergency nurses and acute medical nurses. The MBI was initially used on people working in public services and health care. The instrument consists of 22 items across three subscales of Emotional Exhaustion ( 8 items), Depersonalisation ( 5 items) and Personal Accomplishment ( 9 items). Responses to scale items range from 'never' $=0$ to 'everyday' $=6$. The scores for each subscale are calculated individually. Total subscale scores are categorised as high, moderate or low as defined by the cut-off points of the MBI (see Table 1). Higher scores on Emotional Exhaustion and Depersonalisation are viewed as negative outcomes and suggest higher burnout, whereas higher scores on Personal Accomplishment are viewed as positive outcomes and suggest lower burnout. The MBI is a universally recognised tool and reliability and validity have been well established by previous researchers ${ }^{[48]}$. Cronbach's alpha is used as a measure of internal consistency and an acceptable level of consistency exceeds $0.70^{[49]}$. In a study of burnout in 820 nurses, Vahey et al (2004) reported alpha values of between 0.71- 0.94 for the subscales of the MBI. 


\subsection{Sample}

The study involved a total population sample of all registered nurses within the Emergency Department and one acute medical unit in one regional hospital in the Republic of Ireland. The total number in the target population was 61 (31 emergency nurses and 30 medical nurses).

\subsection{Data collection}

A letter of invitation/explanation was sent via the hospital's internal mailing system to each nurse, along with the demographic questionnaire, a copy of the MBI and a stamped addressed envelope. A reminder letter was sent to all nurses two weeks after the first invitation to participate. Completed questionnaires were returned to the principal investigator's private address in the stamped addressed envelope provided. Data collection took place during February 2011.

\subsection{Data analysis}

Data were analysed using Statistical Package for the Social Sciences (SPSS) Version 17. Descriptive statistics (frequencies, mean) were used to facilitate and interpret the data collected. Non-parametric methods were used to analyse the data, as the strict assumptions for parametric tests were not met. The Mann-Whitney U test was used to test for differences in burnout levels between nurses in the two clinical areas, differences in burnout subscale scores of male and female nurses, and differences in burnout levels between those considering and not considering leaving the nursing profession. The Kruskal-Wallis Test was used to compare the scores on the burnout subscales for the three marital status groups (single, married, other than). Spearman's Rank Order Correlation was used to describe the strength and direction of the relationship between burnout and length of time working in the study area, number of hours worked per week, age and episodes of sick leave taken in the previous 12 months.

\subsection{Ethical issues}

Ethical approval was obtained from the University of Ulster School of Nursing Filter Committee and from the participating hospital. A license was granted from Mind Garden Inc. that permitted the researchers to administer the MBI. Respondents were provided with an assurance of confidentiality, anonymity and voluntary participation. Respondents were provided with a written explanation of the purpose and aims of the study, and information was provided on how to access the Hospital's Occupational Health Department if concerns arose as a result of participation in the study. Respondents were not asked to sign a written consent form, as consent was implied from the completion of the anonymous questionnaires. Data gathered were stored in a secure locked file cabinet and a password protected computer and was not made available to anyone outside the research team.

\section{Results}

A total of 49 questionnaires were returned from the 61 distributed. One incomplete questionnaire was discarded. The response from emergency nurses was $83.8 \%(n=26)$ and from nurses working on the medical unit the response rate was $73.3 \%(n=22)$. The overall response rate was $78.6 \%$. The majority of the respondents were female $(n=40,83.3 \%)$. The sample comprised of 25 married, 17 single and 6 'other' respondents. Age ranged from 25-50 years and the mean age was 37 years. Reliability tests demonstrated acceptable Cronbach's alpha values (Emotional Exhaustion $\alpha=0.91$, Depersonalisation $\alpha=0.83$, Personal Accomplishment $\alpha=0.76$ ).

\subsection{Prevalence of burnout in emergency nurses and medical nurses}

More than half of medical nurses $(n=12,54.5 \%)$ reported high levels of Emotional Exhaustion, while 38.4\% of emergency nurses $(n=10)$ reported high levels of Emotional Exhaustion. Twelve emergency nurses $(46 \%)$ had high levels of Depersonalisation, while 27.2\% $(n=6)$ of medical nurses had high Depersonalisation levels, and 15\% $(n=4)$ of emergency nurses and 9\% $(n=2)$ of medical nurses reported low levels of Personal Accomplishment. A Mann-Whitney $\mathrm{U}$ 
test revealed no significant difference in Emotional Exhaustion, Depersonalisation or Personal Accomplishment levels between medical nurses and emergency nurses. The mean scores for the three subscales of the MBI are presented in Table 1.

Table 1. MBI sub-scale categorisation and mean scores

\begin{tabular}{llll}
\hline $\begin{array}{l}\text { Burnout subscale categorisation and } \\
\text { mean scores }\end{array}$ & Emergency nurses & Medical nurses & $\begin{array}{l}\text { Significance level } \\
\text { (Mann-Whitney U) }\end{array}$ \\
\hline $\begin{array}{l}\text { Emotional exhaustion } \\
\quad \text { High: } 27 \text { or over } \\
\quad \text { Moderate: } 17-26\end{array}$ & 24.61 & & \\
$\quad$ Low: $0-16$ & & 25.86 & .528 \\
Depersonalisation & & & \\
$\quad$ High: 13 or over & 11.92 & 8.63 & .113 \\
$\quad \begin{array}{l}\text { Moderate: } 7-12 \\
\text { Low: } 0-6\end{array}$ & & & \\
Personal accomplishment & & & \\
$\quad$ High: $0-31$ & & 30.18 & .828 \\
$\quad$ Moderate: $32-38$ & 29.19 & & \\
$\quad$ Low: 39 or over & & & \\
\hline
\end{tabular}

\subsection{The influence of job-related and personal factors on burnout}

A Mann-Whitney U test revealed that there were no statistically significant differences in the MBI subscale scores of males $(M d=4, n=8)$ and females ( $M d=2.5, n=40)$, although males had significantly higher scores on one item of the Depersonalisation subscale, namely; 'I feel recipients blame me for some of their problems',

$$
U=86, z=-2.079, p=.038, r=.30
$$

The relationship between the MBI subscales and age was investigated using Spearman's Rank Order Correlation (rho). A significant negative correlation was found between age and Depersonalisation

$$
(r h o=-.317, n=48, p=.028)
$$

with higher levels of Depersonalisation associated with younger respondents. No other significant age differences were found in relation to Emotional Exhaustion or Personal Accomplishment.

A Kruskal-Wallis test revealed a statistically significant difference in the level of Depersonalisation across the three different marital status groups

$$
\text { (single } n=17 \text {, married } n=25 \text {, other } n=6, \chi^{2}(2, n=48)=8.84, p=.012 \text { ) }
$$

Single nurses recorded a higher mean score (13.5) than married nurses (9.6) and nurses belonging to the 'other' group (4.8) (see Figure 1).

A further post-hoc Mann-Whitney U test found that single nurses had significantly higher levels of Depersonalisation than nurses belonging to the 'other' group $(p=.003)$. No other significant differences were detected between single, married and 'other' nurses, or on the other subscales of the MBI.

Nurses reported that they had worked in the clinical area from 2 - 20 years (average 8.9 years). The relationship between Emotional Exhaustion, Depersonalisation and Personal Accomplishment and length of time working as a registered nurse 
in the clinical area was investigated using Spearman's Rank Order Correlation $(r h o)$. None of these findings reached statistical significance.

Participants were asked 'how many episodes of sickness have you had off work in the last 12 months?' Responses ranged from 0 - 5 episodes, with an average of 1.18 episodes (medical nurses $=1.27$, emergency nurses $=1.11$ ). A Spearman's Rank Order Correlation (rho) did not find any significant relationship between episodes of sick leave taken and burnout.

Figure 1. Mean depersonalisation scores

for marital status

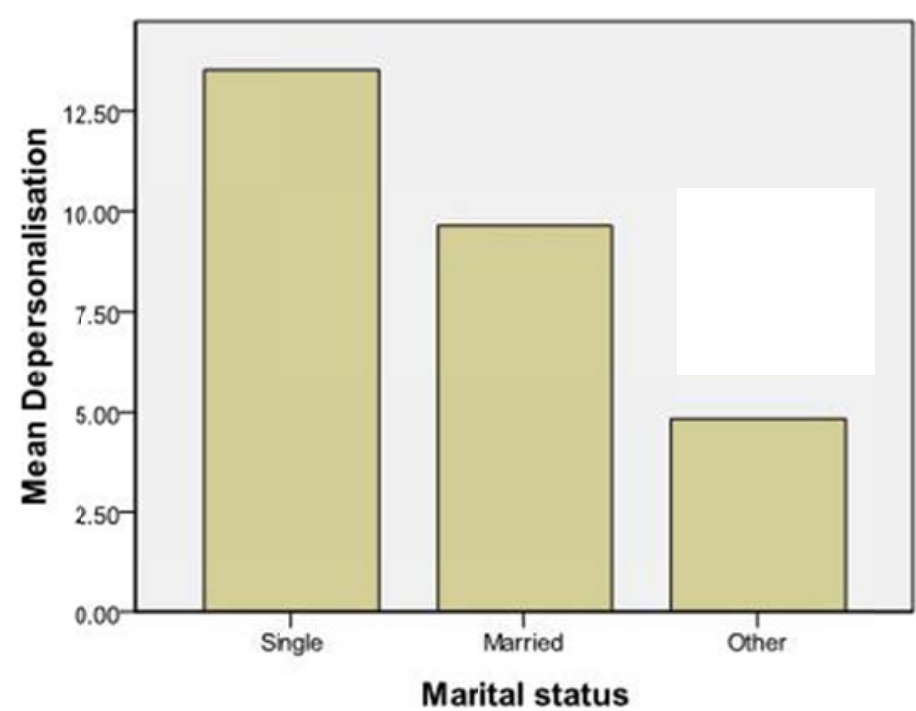

Respondents indicated that they worked between 8 hours and 37.5 hours per week. The average number of hours worked per week for the sample was 32.81 hours. 37.5 hours per week was the most frequently indicated response and was given by $39.6 \%$ of respondents $(n=19)$. Using Spearman's Rank Order Correlation, a significant positive correlation was detected between Emotional Exhaustion and hours worked per week

$$
(r h o=.430, n=48, p=.002)
$$

and between Depersonalisation and hours worked per week

$$
(r h o=.433, n=48, p=.002)
$$

Higher levels of Emotional Exhaustion and Depersonalisation were associated with an increase in hours worked per week. The relationship between Personal Accomplishment and hours worked per week was not found to be significant.

Participants were asked if they had considered leaving the nursing profession. Fifty-six percent of the overall sample indicated that they had considered leaving the nursing profession. Sixty-nine percent of emergency nurses $(n=18)$ indicated that they had considered leaving the profession, while forty percent of medical nurses $(n=9)$ had considered leaving the profession. A Mann-Whitney $U$ test did not reveal any significant difference in Emotional Exhaustion, Depersonalisation and Personal Accomplishment levels between those considering leaving the nursing profession and those not considering leaving.

\section{Discussion}

The findings confirm the presence of burnout in the nurses studied and are in keeping with what previous studies have reported $^{[50,51]}$. The findings of this study suggest that although many of the nurses reported moderate levels of Emotional 
Exhaustion and Depersonalisation, they also experience a sense of achievement and fulfilment in their job, as reflected in the mean Personal Accomplishment scores. This sense of personal achievement and fulfilment may be due to perceived enrichments or rewards obtained on the job. These enrichments or rewards may take the form of salary and related benefits, recognition from colleagues and patients, or a sense of fairness and community.

The present study found that there was an increased prevalence of medical nurses who reported higher levels of Emotional Exhaustion than their emergency nurse colleagues. The study also found an increased prevalence of emergency nurses who reported higher levels of Depersonalisation than their medical nurse colleagues, these findings however were not significant. Gillespie and Melby ${ }^{[43]}$ in a study of 30 emergency nurses and acute medical nurses also found that there was an increased prevalence of nurses working in acute medicine $(56 \%)$ who experience higher levels of Emotional Exhaustion than emergency nurses (20\%). Whilst it is recognised that emergency nurses are considered at risk of burnout ${ }^{[39]}$, it has been suggested that nurses of a narrower specialism may possess a greater sense of professional effectiveness than nurses from a broader specialism, such as general medicine ${ }^{[50]}$. While emergency nurses regularly confront stressors in the form of overcrowding, noise, verbal abuse and caring for acutely unwell patients, it is recognised that they can also possess a range of enhanced skills that contributes significantly to increased efficiencies in the management of patients and improves patient flow through departments ${ }^{[52]}$. The utilisation of these additional skills may increase personal satisfaction as the emergency nurses can see tangible outcomes from their own interventions, possibly having a buffering effect on stress and burnout.

Previous studies on burnout have consistently associated burnout with age. As in previous studies ${ }^{[1,53]}$ younger, more recently qualified nurses in this study reported higher burnout levels compared to older, more experienced nurses . It has been suggested that young and inexperienced nurses face an initial shock when confronted with the realities of the job they have chosen and experience early burnout as a result ${ }^{[25]}$. On the other hand older, more experienced nurses may moderate the demands of work by pacing themselves and may develop a tolerance of environmental factors that would otherwise prove stressful $^{[54]}$.

Depersonalisation levels were found to be highest for single nurses. According to Maslach et al ${ }^{[7]}$ unmarried people are more prone to burnout than married people. Married people have been found to have higher levels of satisfaction with life and feelings of happiness than people who are not married ${ }^{[55]}$. It has been suggested that the psychological protection and healing support provided by a marital partner appears to be helpful in buffering the emotional stress and anxiety experienced by nurses in the provision of patient care ${ }^{[56]}$. A marital partner may provide the nurse with social support that allows for the ventilation of feelings of stress, creates a sense of being valued and recognised outside of the work environment.

In previous research males have been found to report higher levels of Depersonalisation ${ }^{[36]}$. It may be that the human qualities of gentleness, empathy and understanding are innately female qualities and that males, being less well equipped with these qualities, feel more depersonalised. Unfortunately this idea supports the concept of gender stereotyping; males are more likely to be confrontational and females are more likely to be submissive and caring, a view that Maslach et al ${ }^{[7]}$ issued a caution about. Other researchers however, have found that females report higher levels of burnout ${ }^{[28]}$ and it is thought this may be a consequence of women having to bear a greater burden of caring and greater responsibility for the home than men $\mathrm{do}^{[57]}$.

The findings of previous research on the relationship between hours worked per week and burnout have been mixed. Several researchers have found that the number of hours worked as a nurse was positively associated with Emotional Exhaustion and Depersonalisation ${ }^{[25,58]}$. Others however did not find that the number of hours worked per week had a significant influence on burnout scores ${ }^{[30]}$. It may be that nurses who work longer hours experience greater burnout because they have more exposure to the demands of a stressful work environment and this chronic exposure to stress eventually leads to an increase in their level of burnout. Another explanation is that nurses who work longer hours are 
more is affected by the 'routinization of the job ${ }^{[6]}$ in which tasks take on an everyday familiarity and the work fails to provide a sense of challenge and excitement. Nurses who spend longer at work may also suffer from greater disruption to home and family life ${ }^{[58]}$, this disruption may result in increased stress levels as there is not the desired time available to spend on child-rearing, home maintenance, hobbies and social engagement.

Previous research has linked burnout to increased absenteeism ${ }^{[59]}$. In a systematic review of the predictors of nurse absenteeism in hospitals, Davey et al ${ }^{[31]}$ found that one dimension of burnout (Personal Accomplishment) was significantly and negatively related to absenteeism- as levels of Personal Accomplishment increased, absenteeism decreased. This indicates that nurses who felt they were successful and able to achieve their goals were less absent from work. While it has been acknowledged that absenteeism places extra pressure on nurses who stand in for absent colleagues ${ }^{[60]}$, it has been suggested that absenteeism may help to prevent burnout, allowing the nurse to return to work with renewed strength ${ }^{[19]}$. Absenteeism gives the nurse time away from the stressful work environment, provides the opportunity to engage social support mechanisms and allows the nurse the time to address his or her feelings of burnout.

It has been found by previous researchers that an increase in the length of time working as a nurse resulted in lower levels of Emotional Exhaustion ${ }^{[61]}$ and Depersonalisation ${ }^{[44]}$. It has been suggested that nurses with more work experience report less burnout because of their high professional title, experience, self-control and a well-rounded psychological coping mechanism ${ }^{[20]}$. It may be that more senior nurses have lower levels of burnout because they are confident about the role they play in the organisation, have well established relationships with co-workers and management and receive more recognition for the job they do. Maslach et al ${ }^{[7]}$ suggested that those who burn out early in their careers are likely to quit their jobs, leaving behind the survivors who consequently exhibit lower levels of burnout. Other researchers have, however, suggested that senior nurses may experience higher burnout levels because their jobs have become too predictable on a day to day basis ${ }^{[36]}$ or they may want to move on in life coupled with the difficulty in realising it ${ }^{[57]}$. This point is particularly valid in the current economic climate in Ireland as the recruitment moratorium, wage cuts and the housing collapse makes it difficult for nurses to change their job or career without incurring serious financial implications.

It has been suggested that one of the biggest threats to the effective delivery of health care services within the public sector may be the nursing personnel who either quit or consider doing so ${ }^{[62]}$. The finding that $56 \%$ of the overall sample in this study indicated that they had considered leaving the nursing profession has implications for the future of nursing. When a staff member leaves an organisation, the knowledge, skill and experience that the person has brought to, and gained at, the organisation is lost ${ }^{[63]}$. Staff turnover is costly for the organisation and it can take new staff a long period of time to become accustomed to the running of the organisation.

\section{Limitations}

The study has a number of limitations that should be considered. First, the sample was small and focused on two specific clinical areas, therefore the findings need to be interpreted with caution due to the small sample size and lack of statistical power and cannot be generalised beyond the sample population.

Second, the study relied on self-report measures only. Self-reports methods create the potential for bias, respondents may overestimate or underestimate their level of burnout. Reliance on instruments and procedures hinders the connection between research and everyday life ${ }^{[64]}$. It is advisable that future research in the area use multi-method measures to obtain a more comprehensive view of burnout in nurses.

Third, the data were collected at a single point in time. A future study of longitudinal design would provide a more substantive understanding of the concept. Longitudinal study design allows investigators to examine the developmental process by observing changes in individuals over time ${ }^{[65]}$. 
Finally, the data did not meet the stringent assumptions for parametric tests and therefore used non- parametric tests. According to Pallant ${ }^{[66]}$ non-parametric tests are not as powerful as parametric tests, and tend to be less sensitive in detecting a difference or relationship among groups.

\section{Recommendations}

Burnout has been identified as a serious problem for the nursing profession ${ }^{[27]}$. According to Maslach et al ${ }^{[7]}$ burnout leads to lower productivity and effectiveness at work and is associated with decreased job satisfaction and a reduced commitment to the organization. Therefore, it is vital that the presence of burnout is acknowledged by nursing leaders and managers so that measures can be taken to alleviate burnout and its effects. Sadovich ${ }^{[67]}$ recommended that nurse leaders can take small incremental steps to create more supportive working environments that allows for flexible working schedules, facilitates staff input and encourages learning. Halbesleben ${ }^{[68]}$ recommended that staff be involved in efforts taken to reduce stress and burnout as they best understand the processes that are stressful to them and consequently have a vested interest in the process. Illhan et al ${ }^{[25]}$ recommended that organizations attempt to reduce burnout through interventions such as decreasing long hours, rotational working between units, team building, stress management training and regular staff meetings. It has been suggested that early recognition of burnout will contribute to the growth of professionalism, to the change in the structure of the working environment and to the provision of a quality service ${ }^{[69]}$.

Future research in the area of burnout in nurses should involve a larger sample and incorporate a multi-method design, which would facilitate a more comprehensive understanding of burnout in nurses. This study has shown that burnout is prevalent in the sample of emergency department and medical nurses, it is therefore vital that nurse managers recognise the existence of burnout and formulate programmes to alleviate and reduce its impact on patient care, the individual nurse and the organisation. In view of the findings of this study, it is recommended that programmes to reduce burnout should be targeted at nurses who have reported higher levels of burnout, namely; younger nurses, single nurses, males and those who work the greatest number of hours per week.

It is further recommended that nurses are encouraged to take responsibility for their own well-being, including identifying work-related stressors, active participation in measures to reduce stress and being vigilant for signs of stress and burnout in colleagues.

\section{Conclusion}

This study consolidates existing research on burnout in nurses. Although no statistically significant differences were found in burnout levels between emergency nurses and medical nurses, this study has confirmed that burnout is prevalent in the nurses sampled. The results have also demonstrated that, despite the moderate levels of Emotional Exhaustion and Depersonalisation reported by the nurses, they also experience a sense of self-worth and achievement in their work.

The study has also confirmed that a number of job-related and personal factors are significantly associated with burnout, and that younger and single nurses are most at risk for burnout.

This study has already made an impact on practice. Through a collaborative approach involving nursing management and the Occupational Health Department within the research hospital, nurses have been provided with written and verbal information in relation to how to make a self-referral to the Occupational Health Department if they were concerned about their level of stress or burnout. A follow-up evaluation of this will take place within one year. The findings of this study will be further used to assist nurse management in designing programmes to reduce the impact of burnout for the individual nurse and for the organisation. Reduction in the overall levels of workplace stress and burnout will help to create an environment that promotes personal growth, increases productivity and positively influences patient care. 


\section{References}

[1] Demerouti E, Bakker AB, Nachreiner F, Schaufeli WB. A model of burnout and life satisfaction amongst nurses. J Adv Nurs, 2000; 32(2):454-464. PMid:10964195 http://dx.doi.org/10.1046/j.1365-2648.2000.01496.x

[2] Scott CR. Communication, Social Support, and Burnout: A Brief Literature Review. Micro Organizational Communication Theory and Research. 2001[cited Jan 2014 Jan 4] Available from:

http://www.gslis.utexas.edu/ ssoy/pubs/micro-communication/2micro.htm

[3] Moore A. Dark Mood. World Irish Nurs. 2010; 18(6): 20-21.

[4] Keating A. New year, old issues. World of Irish Nurs. 2010;18(2): 21.

[5] Kilcoyne M, Dowling M. Working in an overcrowded accident and emergency department: nurses' narratives. Aus J Adv Nurs. 2007; 25(2): 21- 27.

[6] Freudenberger HJ. Staff Burn-out. Journal of Social Issues. 1974; 30(1): 159-165. http://dx.doi.org/10.1111/j.1540-4560.1974.tb00706.x

[7] Maslach C, Schaufeli, WB, Leiter, MP. Job Burnout. Annual Review of Psychology. 2001; 52: 397-422. PMid:11148311 http://dx.doi.org/10.1146/annurev.psych.52.1.397

[8] Maslach C, Jackson, SE. The measurement of experienced burnout. Journal of Occupational Behaviour. 1981; 2: 99-113. http://dx.doi.org/10.1002/job.4030020205

[9] Malliarou MM, Moustaka EC, Konstantinidis TC. Burnout in nursing personnel in a regional university hospital. Health Science Journal. 2008; 2(3); 140-152.

[10] Leiter MP, Maslach C. The impact of interpersonal environment on burnout and organizational commitment. Journal of Organizational Behavior. 1988; 9: 297-308. http://dx.doi.org/10.1002/job.4030090402

[11] Joinson C. Coping with compassion fatigue. Nursing. 1992; 22(4): 116-121. PMid:1570090 http://dx.doi.org/10.1097/00152193-199204000-00035

[12] Figley CR. Treating compassion fatigue. New York: Brunner- Routledge; 2002. PMid:12412153

[13] Harrowing JN. Compassion practice by Ugandan nurses who provide HIV care. The online Journal of Nursing Issues [Internet]. 2011[cited 2010 Mar 6];16 (1). Available from:

http://www.nursingworld.org/MainMenuCategories/ANAMarketplace/ANAPeriodicals/OJIN/TableofContents/Vol-16-2011/No 1-Jan-2011/Compassion-Practice-and-HIV-Care-.html

[14] Boyle DA. Countering compassion fatigue: a requisite nursing agenda. The Online Journal of Issues in Nursing [Internet]. 2011 [cited 2010 Jan 3]; 16(1). Available from:

http://www.nursingworld.org/MainMenuCategories/ANAMarketplace/ANAPeriodicals/OJIN/TableofContents/Vol-16-2011/No 1-Jan-2011/Countering-Compassion-Fatigue.html

[15] Sabo B. Reflecting on the concept of compassion fatigue. Online Journal of Issues in Nursing [Internet]. 2011 [cited 2010 Jan 3]; 16 (1). Available from:

http://www.nursingworld.org/MainMenuCategories/ANAMarketplace/ANAPeriodicals/OJIN/TableofContents/Vol-16-2011/No 1-Jan-2011/Concept-of-Compassion-Fatigue.html

[16] Figley CR. Compassion fatigue: Coping with secondary traumatic stress disorder in those who treat the traumatized. New York: Brunner-Mazel; 1995.

[17] Maslach C, Leiter MP. The truth about burnout. San Francisco: Jossey-Bass; 1997. PMid:9332965

[18] World Health Organisation.International Statistical Classification of Diseases and Related Health Problems 10th ed. Geneva: World Health Organisation; 1992.

[19] Bagan Y. Burnout and absenteeism among nurse in health care management. Journal of Academy of Business and Economics [Internet]. 2005[cited 2010 Mar 6]; 5(1). Available from: http://www.freepatentsonline.com/article/Journal-Academy-Business-Economics/149213873.html

[20] Lei W, Hee KY, Dong W. A review of research and strategies for burnout among Chinese nurses. British Journal of Nursing. 2010; 19 (13); 844-850. PMid:20606615 http://dx.doi.org/10.12968/bjon.2010.19.13.48862

[21] Poncet MC, Toullic P, Papazian L, Kentish-Barnes N, Timsit J-F, Pochard F, Chevret S, Schlemmer B, Azoulay E. Burnout Syndrome in Critical Care Nursing Staff. American Journal of Respiratory and Critical Care Medicine. 2006; 175: 698-704. PMid:17110646 http://dx.doi.org/10.1164/rccm.200606-806OC

[22] Vahey DC, Aiken LH, Sloane DM, Clarke SP, Vargas D. Nurse Burnout and Patient Satisfaction. Medical Care. 2004; 42(2): 57-66.

[23] Leiter MP, Harvie P, Frizzell C. The correspondence of patient satisfaction and nurse burnout. Social Science \& Medicine. 1998; 47(10): 1611-1617. http://dx.doi.org/10.1016/S0277-9536(98)00207-X 
[24] Aiken LH, Clarke SP, Sloane DM, Sochalski J, Silber JH. Hospital nurse staffing and patient mortality, nurse burnout, and job dissatisfaction. The Journal of the American Medical Association. 2002; 288(16): 1987-1993. http://dx.doi.org/10.1001/jama.288.16.1987

[25] İlhan MN, Durukan E, Taner E, Maral I, Bumin MA. Burnout and its correlates among nursing staff: questionnaire survey. Journal of Advanced Nursing. 2007; 61(1): 100-106. PMid:18034813

[26] Dos Santos FE, Alves JA, Rodrigues AB. Burnout syndrome in nurses in an Intensive Care Unit. Einstein. 2009;7(1 Pt 1): 58-63.

[27] Akgun S, Al-Assaf AF, Bakan C. Reducing burnout among hospital professionals: EAP's can help identify and alleviate the factors that cause burnout and improve the health and performance of hospital staff. The Journal of Employee Assistance [Internet]. 2008 [cited 2010 Mar 6]; 38(3). Available from:

http://www.thefreelibrary.com/_/search/Search.aspx?SearchBy=0\&Word=burnout\&hospital\&profe ssions\&Search $=$ Search $\& B Y=3$

[28] Lin F, St John W, McVeigh C. Burnout among hospital nurses in China. Journal of Nursing Management. 2009; 17(3): $294-301$. PMid:21456318 http://dx.doi.org/10.1111/j.1365-2834.2008.00914.x

[29] Sahraian A, Fazelzadeh A, Mehdizadeh AR, Toobaee, SH. Burnout in hospital nurses: a comparison of internal, surgery, psychiatry and burns wards. International Nursing Review. 2008; 55(1): 62-67. PMid:18275537 http://dx.doi.org/10.1111/j.1466-7657.2007.00582.x

[30] Gombor A. Burnout in Hungarian and Swedish Emergency Nurses: Demographic Variables, Work-Related Factors, Social Support, Personality, and Life Satisfaction as Determinants of Burnout. Dissertation, (PhD). University of Eötvös Lorand, Budapest. Available from: http://www.pszichologia.phd.elte.hu/vedesek/2010/Burnout.pdf

[31] Davey MM, Cummings G, Newburn-Cook CV, Lo EA. Predictors of nurse absenteeism in hospitals: a systematic review. Journal of Nursing Management. 2009; 17(3): 312-330. PMid:19426368 http://dx.doi.org/10.1111/j.1365-2834.2008.00958.x

[32] Westman M, Etzion D. The impact of vacation and job stress on burnout an absenteeism. Psychology and Health. 2001; 16: 595-606. PMid:22804501 http://dx.doi.org/10.1080/08870440108405529

[33] Le Blanc PM, De Jorge J, De Rijk AE, Schaufeli WB. Well-being of Intensive care nurses (WEBIC): a job analytic approach. Journal of Advanced Nursing. 2001; 36(3): 460-470. PMid:11686761 http://dx.doi.org/10.1046/j.1365-2648.2001.01994.x

[34] Bakker AB, Le Blanc, PM, Schaufeli, WB. Burnout contagion among intensive care nurses. Journal of Advanced Nursing. 2005; 51(3): 276-287. PMid:16033595 http://dx.doi.org/10.1111/j.1365-2648.2005.03494.x

[35] Edwards D, Burnard P, Coyle D, Fothergill A, Hannigan B. Stress and burnout in community mental health nursing: a review of the literature. Journal of Psychiatric and Mental Health Nursing. 2000; 7: 7-14. PMid:11022506 http://dx.doi.org/10.1046/j.1365-2850.2000.00258.x

[36] Kilfedder CJ, Power KG, Wells TJ. Burnout in psychiatric nurses. Journal of Advanced Nursing. 2001; 34(3): 383-396. PMid:11328444 http://dx.doi.org/10.1046/j.1365-2648.2001.01769.x

[37] Payne N. Occupational stressors and coping as determinants of burnout in female hospice nurses. Journal of Advanced Nursing. 2001; 33(3): 396-40. PMid:11251727 http://dx.doi.org/10.1046/j.1365-2648.2001.01677.x

[38] Kitze S, Rodrigues AB. Burnout in Oncology: a study of Nursing Professionals. Einstein (São Paulo). 2008; 6(2): $128-133$.

[39] Kalemoglu M, Keskin O. Burnout syndrome at the emergency service. Scandinavian Journal of Trauma, Resuscitation and Emergency Medicine. 2006; 14; 37-40.

[40] Browning L, Ryan CS, Thomas S, Greenberg M, Rolniak S. Nursing Specialty and burnout. Psychology, Health \& Medicine. 2007; 12(2): 248-254. http://dx.doi.org/10.1080/13548500600568290

[41] McCarthy VJC, Power S, Greiner BA. Perceived occupational stress in nurses working in Ireland. Occupational Medicine. 2010; 60(8): 604-610. PMid:20889816 http://dx.doi.org/10.1093/occmed/kqq148

[42] Escribà-Agüir V, Martín-Baena D, Pérez-Hoyos S. Psychosocial work environment and burnout among emergency medical and nursing staff. International Archives of Occupational and Environmental Health. 2006; 80(2): 127-133. PMid:16710712 http://dx.doi.org/10.1007/s00420-006-0110-y

[43] Gillespie M, Melby V. Burnout among nursing staff in accident and emergency and acute medicine: a comparative study. Journal of Clinical Nursing. 2003 12(6): 842-851. PMid:14632977 http://dx.doi.org/10.1046/j.1365-2702.2003.00802.x

[44] Oncel S, Ozer ZC, Efe E. Work-related stress, burnout and job satisfaction in Turkish midwives. Social Behavior and Personality. 2007; 35(3): 317-328. http://dx.doi.org/10.2224/sbp.2007.35.3.317

[45] Gustafsson G, Persson B, Eriksson S, Norberg A, Strandberg G. Personality traits among burnt out and non-burnt out health-care personnel at the same workplaces: A pilot study. International Journal of Mental Health Nursing. 2009; 18: 336-348. PMid:19740143 http://dx.doi.org/10.1111/j.1447-0349.2009.00623.x

[46] Houser J. Nursing Research: Reading, Using and Creating Evidence. London: Jones and Bartlett Publishers International; 2008.

[47] Maslach C, Jackson S. MBI-Human Services Survey. Mind Garden Inc.: Merlo Park; 1986 
[48] Galanakis M, Moraitou M, Garivaldis FJ, Stalikas A. Factorial Structure and Psychometric Properties of the Maslach Burnout Inventory (MBI) in Greek Midwives. Europe's Journal of Psychology. 2009; 4: 52-70.

[49] Macnee CL, McCabe S. Understanding Nursing Research. 2nd ed. Philadelphia: Lippincott Williams \& Wilkin; 2008.

[50] Jaracz K, Górna K, Konieczna J. Burnout, stress and styles of coping among hospital nurses. Annales Academiae Medicae Bialostocensis. 2005; 50(1): 216-219.

[51] Grau-Alberola E, Gil-Monte PR, García-Juesas JA, Figueiredo-Ferraz H. Incidence of burnout in Spanish nursing professionals: A longitudinal study. International Journal of Nursing Studies. 2010; 47: 1013-1020. PMid:20096838 http://dx.doi.org/10.1016/j.ijnurstu.2009.12.022

[52] National Council for the Professional Development of Nursing and Midwifery. Enhanced Nursing Practice in Emergency Departments. Dublin: NCMN; 2008.

[53] Meltzer LS, Huckabay LM. Critical care nurses' perceptions of futile care and its effects on burnout. American Journal of Critical Care. 2004; 13(3): 202-208. PMid:15149054

[54] Lang GM, Pfister EA, Siemens MJ. Nursing Burnout: Cross- Sectional Study at a Large Army Hospital. Military Medicine. 2010; 175(6): 435-441. PMid:20572477 http://dx.doi.org/10.7205/MILMED-D-09-00284

[55] Williams E, Francis L, Village A. Marriage, religion and human flourishing: how sustainable is the classic Durkheim thesis in contemporary Europe? Mental Health, Religion \& Culture.2010; 13(1): 93-104. http://dx.doi.org/10.1080/13674670903203766

[56] Ifeagwazi CM. The influence of marital status on self-report of symptoms of psychological burnout among nurses. Omega: Journal of Death and Dying. 2006; 52(4); 359- 373. http://dx.doi.org/10.2190/DNBR-8E28-JXTM-MEAW

[57] Chayu T, Kreitler S. Burnout in Nephrology Nurses in Israel. Nephrology Nursing Journal. 2011; 38(1): 65-77. PMid:21469556

[58] Patrick K, Lavery JF. Burnout in Nursing. Australian Journal of Advanced Nursing. 2007; 24(3): 43-48. PMid:17518165

[59] Alexander LL. Burnout: Impact on Nursing. California: CME Resource [Internet]. 2009 [cited 2011 Feb 20] Available from: http://www.netcegroups.com

[60] Nyathi M, Jooste K. Work conditions that contribute to absenteeism among nurses in a provincial hospital in the Limpopo Province. Curationis. 2008; 31(1): 28-37. PMid:18592946 http://dx.doi.org/10.4102/curationis.v31i1.903

[61] Yousefy AR, Ghassemi Gh.R. Job burnout in psychiatric and medical nurses in Isfahan, Islamic Republic of Iran. Eastern Mediterranean Health Journal. 2006; 12(5): 662-669. PMid:17333807

[62] Pienaar JW, Bester CL. The impact of burnout on the intention to quit among professional nurses in the Free State region- a national crisis? South African Journal of Psychology. 2011; 41(1): 113-122. http://dx.doi.org/10.1177/008124631104100112

[63] Naud M, McCabe R. Increasing retention of nursing staff at hospital: aspects of management and leadership. Australian Bulletin of Labour. 2005; 31(4): 426-439.

[64] Kane E, O’Reilly De Brun, M. Doing your own research. London: Marion Boyers Publishers; 2001.

[65] Nevid JS. Psychology, Concepts, and Applications. 3rd ed. Boston: Houghton Mifflin Company; 2009.

[66] Pallant J. SPSS Survival Manual. 3rd ed. England: Open University Press, McGraw-Hill: 2007.

[67] Sadovich JM. Work Excitement in Nursing: An Examination of the Relationship Between Work Excitement and Burnout. Nursing Economics. 2005; 23(2): 91-96. PMid:15881495

[68] Halbesleben, JRB. Addressing stress and beating burnout. Healthcare Executive. 2010; 58-60. PMid:20349765

[69] Malliarou MM, Moustaka, EC, Konstantinidis, TC. Burnout in nursing personnel in a regional university hospital. Health Science Journal. 2008; 2(3): 140-152. 